\begin{abstract}
Purpose To investigate the efficacy and complications associated with dose increments of botulinum toxin-A (BTA) for comitant horizontal strabismus patients.

Methods Twenty-five esotropic (ET) and 45 exotropic (XT) patients received 2.5-20 U of BTA injection. Parameters for achieving less than 10 prism dioptres (pd) of horizontal deviation and percentage correction of the pretreatment deviation were assessed for injections of less than $10 \mathrm{U}$ and more than $10 \mathrm{U}$ of BTA. Induced ptosis and vertical deviation were examined within and after 6 months of

with more than $10 \mathrm{U}$ of BTA injection. In about a year, induced vertical deviation resolved in approximately $40 \%$, and decreased in $30 \%$ of the cases.

Conclusion Increasing the dose of BTA is clinically effective in larger deviations, although statistically indifferent, especially in ET compared with XT. However, an increased dose is accompanied by increased incidence of induced ptosis and vertical deviation. Ptosis is temporary, but vertical deviation may persist for a long time and may present a cosmetic problem for some patients when more than $\mathbf{1 0}$ U of BTA is used.
\end{abstract} follow-up.

Results The mean pretreatment deviations were $38.6 \pm 2.5 \mathrm{pd}$ and $37.6 \pm 1.9 \mathrm{pd}$ for the ET and XT groups, respectively. After receiving 1.6 and 1.5 injections on average, improvement to less than $10 \mathrm{pd}$ at the primary position occurred in $32 \%$ of ET and $22 \%$ of XT patients; the difference was not statistically significant. The percentage corrections of the ET patients were $41.4 \pm 9.3 \%$ and $36.9 \pm 5.6 \%$ in those treated with less than $10 \mathrm{U}$ and more than $10 \mathrm{U}$ of BTA respectively; the difference between the two groups was insignificant. For the XT patients the values were $42.1 \pm 7.4 \%$ and $28.9 \pm 3.5 \%$ respectively, which also were not statistically significantly different. Frequency of induced ptosis was more common in ET than XT patients $(p=0.01)$ and this difference was more pronounced with increased doses of BTA $(7.7 \%$ in ET and $5.3 \%$ in XT patients with less than $10 \mathrm{U}$ of BTA, and $24.0 \%$ in ET and $4.3 \%$ in XT patients with more than $10 \mathrm{U}$ of BTA). Ptosis resolved completely within 6 weeks in all cases. Induced vertical deviation with less than $10 \mathrm{U}$ of BTA was encountered in one case of ET (11.1\%, 9 pd) and in another case of XT $(8.3 \%, 4 \mathrm{pd})$, increasing to $60.0 \%$ (2-20 pd) and $38.8 \%(4-16 \mathrm{pd})$ respectively
Key words Botulinum toxin-A, Complications, Ptosis, Strabismus, Strabismus surgery, Vertical strabismus

Botulinum toxin type-A (BTA) produces a presynaptic blockage by interfering with cholinergic transmission, resulting in a temporary flaccid paralysis of the injected muscle lasting 6-8 weeks. Thus the antagonist of the injected muscle contracts more effectively and corrects the deviation. ${ }^{1,2}$ There are a number of strabismus cases in which the surgical outcome is unpredictable or surgery is not justified, such as in deep amblyopia, reoperation or a small amount of deviation. In addition, some patients are reluctant to have surgery and willing to try other alternatives before a definitive procedure. Botulinum toxin injection has been proved to be a reasonable alternative to strabismus surgery for these selected cases. $^{3-6}$

BTA treatment is advantageous in that it is easily administered in the outpatient clinic with the use of only topical anaesthesia. However, results of this treatment are not as predictable and success rate is not as high as for traditional surgery. ${ }^{7-10}$
E.C. Şener

A.S. Sanaç

Strabismus and Pediatric Ophthalmology Division

Department of

Ophthalmology

Hacettepe University Hospitals

06100 Ankara, Turkey

\section{E.C. Şener}

Strabismus and Pediatric Ophthalmology Division

Department of

Ophthalmology

Hacettepe University

Hospitals

06100 Ankara, Turkey

Tel: +903123104256

$+903124470040$

Fax: +903123094101

e-mail:

ecsener@hacettepe.edu.tr

Received: 3 April 2000 Accepted in revised form: 27 July 2000 
We have shown before in a different set of patients that there is less chance of achieving a post-treatment deviation within 10 prism dioptres (pd) in larger deviations of both esotropes and exotropes. ${ }^{11}$ Increasing the dose was useful only to a certain extent; however, the associated risk of complications was not clearly established in that study. There are two major complications of BTA treatment associated with flaccid paralysis of other extraocular muscles which may be dose dependent: ptosis and induced vertical deviation. This study was performed to evaluate the relative efficacy of an increased dosage of BTA and related complications of treatment in patients with comitant horizontal deviations.

\section{Materials and methods}

In this retrospective study, charts of patients with comitant horizontal deviations treated with BTA injections at our department between 1995 and 1999 were reviewed. Informed consent was obtained from all patients. All patients were evaluated and given BTA treatment by one of the authors. Measurements were done and recorded by the same orthoptist. Before BTA injection, topical cocaine was applied to the conjunctival sac for anaesthesia. Injection was performed under electromyographic control with a monopolar needle. We used the botulinum toxin Dysport (Porton Products, UK) until it was no longer available in Turkey, and have been using Botox (Allergan, USA) since then. There is no nomogram for adjusting the dosage between different brands of BTA in order to achieve a similar clinical effect. Considering our past clinical experience in terms of dose-effect relationship, we have only included the patients receiving the British product for the data analysis. BTA was diluted so that regardless of dose, a bolus of $0.1 \mathrm{ml}$ could be injected. The dose ranged from 2.5 to 20 units depending on the amount of deviation or experience gained from previous injection of that particular patient. Deviations of less than $35 \mathrm{pd}$ received $2.5,5.0$ or $7.5 \mathrm{U}$, and deviations equal to or more than $35 \mathrm{pd}$ received 10,15 or $20 \mathrm{U}$ of BTA. The dose was increased stepwise, for instance from 2.5 to $5.0 \mathrm{U}$, if the previous injection was unsatisfactory.

The inclusion criterion for data analysis required a follow-up period of 12-24 weeks provided that the patient recovered fully from the paralytic effect of the drug. We excluded those patients who had their followup before or later than this time period, or were injected with another brand of BTA. Seventy patients with horizontal comitant strabismus met this criterion, and were included in the study. The data on patients with the toxin-related complication of vertical deviation who were available for longer than 6 months of follow-up were also included in the study.

All patients had undergone a thorough examination including visual acuity measurement, cycloplegic refraction, anterior and posterior segment analysis and complete orthoptic examination. Main indications for BTA treatment were comitant strabismus in which long- term surgical outcome could not be anticipated due to a relatively small angle of deviation, past history of multiple surgeries and deep amblyopia. Patients with large angle strabismus were also given the chance of a BTA trial when they preferred the method over strabismus surgery. The angle of deviation in the primary position was measured with a prism cover-uncover test with full optical correction at distance and near. The Krimsky method was used for patients who were unable to fixate due to low visual acuity.

Two methods were used to evaluate the effect of BTA in strabismus. The first was to determine whether the post-treatment deviation was within $10 \mathrm{pd}$ of straight. We assumed that those patients with a post-treatment deviation within 11-20 pd of straight had a cosmetically acceptable result, unless the patient claimed otherwise. The second method was to calculate the percentage correction of the pretreatment deviation after the pharmacological paralytic effect disappeared, using the following formula:

\section{$100 \times$ (Pretreatment deviation - post-treatment deviation)/pretreatment deviation}

We investigated the efficacy of increasing doses of BTA following the last injection, in separate groups of esotropic and exotropic patients.

We evaluated the incidence of two major complications of BTA in response to dose increments: ptosis and induced vertical deviation. Possibly due to infiltration of toxin into the neighbouring tissues, one can encounter flaccid paralysis in surrounding muscles which causes ptosis and vertical deviation in some cases. In a case of ptosis the levator palpebra superior muscle, and in a case of induced vertical deviation the elevator or depressor muscles, are claimed to be affected by infiltrated toxin. It is quite difficult to make accurate measurements of accompanying slight vertical deviations in patients with large angle horizontal strabismus or whose visual acuity does not allow for satisfactory fixation. Therefore, when analysing the data on vertical deviation we included only those patients in whom fixation was good enough to elicit reproducible measurements.

Ptosis was defined as the upper eyelid covering more than $1.5 \mathrm{~mm}$ of the superior limbus, or a difference of more than $1.0 \mathrm{~mm}$ between upper eyelids, which occurred after BTA injection. In order to quantify vertical deviations, the amount of horizontal deviation was compensated by a prism held in front of the deviating eye and a vertical prism bar was used for the opposite eye.

\section{Results}

Seventy patients with a mean age of $26.1 \pm 0.5$ years (range 11-80 years) were included in the study. Twentyfive of the patients were esotropes. The mean pretreatment deviation was $38.6 \pm 2.5$ pd (range 
Table 1. Angle of deviation after BTA in esotropia and exotropia patients

\begin{tabular}{cccc}
\hline $\begin{array}{c}\text { Residual deviation } \\
\text { after BTA (pd) }\end{array}$ & $\begin{array}{c}\text { Esotropia } \\
(n=25)\end{array}$ & $\begin{array}{c}\text { Exotropia } \\
(n=45)\end{array}$ & $\begin{array}{c}p \\
\text { value }\end{array}$ \\
\hline $0-10$ & $8(32 \%)$ & $10(22 \%)$ & 0.18 \\
$11-20$ & $10(40 \%)$ & $16(36 \%)$ & 0.35 \\
\hline
\end{tabular}

$12-80 \mathrm{pd})$. A total of 38 injections were performed with an average of 1.6 injections per patient (range 1-3 injections).

We enrolled 45 exotropic patients in the study. The mean pretreatment deviation was $37.6 \pm 1.9$ pd (range 8-70 pd). A total of 66 injections were applied with an average of 1.5 injections per patient (range 1-3 injections).

We first evaluated the percentage of patients having correction within $10 \mathrm{pd}$ and $11-20 \mathrm{pd}$ of straight in the primary position of gaze following the last injection (Table 1). The angle of deviation improved to $10 \mathrm{pd}$ of straight in $8(32 \%)$ and to $11-20 \mathrm{pd}$ in $10(40 \%)$ of 25 esotropic patients. The post-treatment deviation decreased below $10 \mathrm{pd}$ in $10(22 \%)$ and to $11-20 \mathrm{pd}$ in 16 $(36 \%)$ of 45 exotropic patients. Although a higher percentage of esotropic patients was corrected to within $10 \mathrm{pd}$ or $11-20 \mathrm{pd}$ compared with the exotropes, the difference was not statistically significant $(p=0.18$ and $p=0.35$ respectively, with the test of two proportions from independent groups).

The effect of a dose increment of BTA on the improvement in deviation was also investigated separately for esotropic and exotropic patients. We have previously found that only large dose increments such as from 2.5 to $10 \mathrm{U}$, and from 2.5 to $20 \mathrm{U}$, made a significant difference in the percentage reduction of the deviation. ${ }^{11}$ Thus, according to the dose of BTA applied, two groups were formed: a first group that received an injection of less than $10 \mathrm{U}$ of BTA $(2.5,5$ or $7.5 \mathrm{U})$ and a second group that received more than $10 \mathrm{U}$ of BTA $(10,15$ or $20 \mathrm{U})$.

The percentage correction of the esotropic patients treated with less than $10 \mathrm{U}$ of BTA was $41.4 \pm 9.3 \%$. The value for esotropic patients treated with more than $10 \mathrm{U}$ of BTA was $36.9 \pm 5.6 \%$. The difference was insignificant with a Mann-Whitney $U$-test $(U=147, p=0.79)$ (Table 2). In the exotropes, the percentage corrections for the group treated with less than $10 \mathrm{U}$ of BTA and for the group treated with more than $10 \mathrm{U}$ of BTA were $42.1 \pm 7.4 \%$ and $28.9 \pm 3.5 \%$ respectively. Again, the difference was not statistically significant $(U=336.5, p=0.12$ ) (Table 2).

There were 19 cases in the esotropia group and 30 cases in the exotropia group fulfilling the inclusion criterion for assessing the induced vertical deviation by BTA (Table 3). There were no cases of induced

Table 2. Percentage correction in esotropia and exotropia patients injected with less than and more than $10 \mathrm{U}$ of BTA

\begin{tabular}{llcc}
\hline & $<10$ U BTA & $\geqslant 10$ U BTA & $p$ value \\
\hline Esotropia & $41.4 \pm 9.3 \%$ & $36.9 \pm 5.6 \%$ & 0.79 \\
Exotropia & $42.1 \pm 7.4 \%$ & $28.9 \pm 3.5 \%$ & 0.12 \\
\hline
\end{tabular}

Table 3. Induced vertical deviation with different doses of BTA injection

\begin{tabular}{lccccc}
\hline & \multicolumn{2}{c}{ Esotropia } & & \multicolumn{2}{c}{ Exotropia } \\
\cline { 2 - 3 } \cline { 5 - 6 } & $<10 \mathrm{U}$ & $\geqslant 10 \mathrm{U}$ & & $<10 \mathrm{U}$ & $\geqslant 10 \mathrm{U}$ \\
& BTA & BTA & & BTA & BTA \\
\hline Hypertropia & $1 / 9^{a}$ & $6 / 10^{b}$ & & 0 & $3 / 18^{c}$ \\
Hypotropia & 0 & 0 & & $1 / 12^{d}$ & $4 / 18^{e}$ \\
Total & $7 / 19(37 \%)$ & & $8 / 30(27 \%)$ \\
${ }^{{ }^{a} 9} \mathrm{pd} ;^{b} 2,4,6,6,16,20 \mathrm{pd} ;^{c} 4,6,12 \mathrm{pd} ;^{d} 4 \mathrm{pd} ;^{e} 4,5,6,16 \mathrm{pd}$.
\end{tabular}

hypotropia in the esotropes. One of 9 injections of less than $10 \mathrm{U}$ of BTA caused hypertropia ( $9 \mathrm{pd})$. Six of 10 injections of more than $10 \mathrm{U}$ of BTA induced an average vertical deviation of $9.0 \mathrm{pd}(2,4,6,6,16,20 \mathrm{pd})$. Among 12 exotropic patients treated with less than 10 units of BTA there was no case of induced hypertropia but one hypotropia of $4 \mathrm{pd}$. Among 18 patients treated with more than $10 \mathrm{U}$ of BTA, 3 cases of induced hypertropia and 4 cases of induced hypotropia were encountered. Average induced hypotropic deviation was $7.8 \mathrm{pd}$ $(4,5,6,16 \mathrm{pd})$ and that of hypertropic deviation was 7.3 pd $(4,6,12 \mathrm{pd})$.

When followed for more than 6 months after the injection (9-27 months, average 13.6 months), the induced vertical deviation disappeared or decreased in most cases (Table 4). Three of 15 patients (20\%) were lost to followup. In 5 patients of the remaining 12 the deviation completely resolved ( $42 \%)$, whereas in 3 it decreased $(25 \%)$ and in 4 remained the same in the long term $(33 \%)$. Complete relief from induced vertical deviation, if it occurred, was found in 13 months on average. Only one exotrope experienced prolonged induced hypotropia of 4 pd with injection of less than $10 \mathrm{U}$ BTA. More than $10 \mathrm{U}$ of BTA caused hypertropia in 2 esotropia patients, while among the exotropia patients 3 had induced hypotropia and 1 had induced hypertropia.

Ptosis, the other common paralytic side effect of BTA, was investigated by regarding every injection as a separate case (Table 5). The frequency of induced ptosis with each injection was $18 \%$ and $5 \%$ for esotropic and exotropic patients respectively. The difference was statistically significant ( $p=0.01$; two proportions from independent groups). More than $10 \mathrm{U}$ of BTA increased the frequency of ptosis compared with less than $10 \mathrm{U}$ of injection in esotropia patients from $8 \%$ to $24 \%$, whereas the frequency remained almost the same in exotropia patients (5\% and $4 \%$, respectively). In only 1 exotropic and 1 esotropic patient was ptosis significant enough to occlude the pupilla. Ptosis was usually mild and did not cause any trouble during the recovery period in most cases. In all patients, ptosis disappeared completely by 6 weeks.

\section{Discussion}

We achieved a post-treatment deviation less than $10 \mathrm{pd}$ of straight in $32 \%$ and within $11-20 \mathrm{pd}$ in $40 \%$ of esotropia patients, while the figures for exotropia patients were $22 \%$ and $36 \%$ respectively. Although the 
Table 4. Progress of induced vertical deviation with BTA in extended follow-up of esotropia and exotropia patients

\begin{tabular}{|c|c|c|c|}
\hline \multirow[b]{2}{*}{ Deviation } & \multirow[b]{2}{*}{ Dose of BTA } & \multicolumn{2}{|c|}{ Induced vertical deviation } \\
\hline & & At $<6$ months & At the last examination ${ }^{a}$ \\
\hline Esotropia & $\begin{array}{l}<10 \mathrm{U} \\
\geqslant 10 \mathrm{U}\end{array}$ & $\begin{array}{r}9 \text { pd hyper } \\
2 \text { pd hyper } \\
20 \text { pd hyper } \\
4 \text { pd hyper } \\
6 \text { pd hyper } \\
6 \text { pd hyper } \\
16 \text { pd hyper }\end{array}$ & $\begin{array}{l}0 \mathrm{pd}, 9 \mathrm{~m} \\
0 \mathrm{pd}, 12 \mathrm{~m} \\
0 \mathrm{pd}, 18 \mathrm{~m} \\
? \\
? \\
4 \text { pd hyper, } 27 \mathrm{~m} \\
6 \text { pd hyper, } 15 \mathrm{~m}\end{array}$ \\
\hline Exotropia & $\begin{array}{l}<10 \mathrm{U} \\
\geqslant 10 \mathrm{U}\end{array}$ & $\begin{array}{l}4 \text { pd hypo } \\
4 \text { pd hypo } \\
6 \text { pd hypo } \\
5 \text { pd hypo } \\
16 \text { pd hypo } \\
4 \text { pd hyper } \\
12 \text { pd hyper } \\
6 \text { pd hyper }\end{array}$ & $\begin{array}{l}4 \mathrm{pd} \text { hypo, } 9 \mathrm{~m} \\
\text { ? } \\
4 \mathrm{pd} \text { hypo, } 18 \mathrm{~m} \\
5 \mathrm{pd} \text { hypo, } 12 \mathrm{~m} \\
16 \mathrm{pd} \text { hypo, } 9 \mathrm{~m} \\
0 \mathrm{pd}, 13 \mathrm{~m} \\
0 \mathrm{pd}, 13 \mathrm{~m} \\
6 \mathrm{pd} \text { hyper, } 9 \mathrm{~m}\end{array}$ \\
\hline
\end{tabular}

${ }^{a}$ Time period between injection and the first time when induced vertical deviation can no longer be measured or the last follow-up.

difference between the groups was not statistically significant, BTA seems to be less satisfactory in exotropic patients compared with esotropic patients. These findings are in agreement with our prior report on another set of patients, in whom less than $10 \mathrm{pd}$ deviation was achieved in $33 \%$ of esotropia and $18 \%$ of exotropia patients. ${ }^{11}$ Biglan et al. ${ }^{8}$ reported that only $13.3 \%$ of exotropia cases with an average of $26.9 \mathrm{pd}$ deviation were controlled with BTA compared with $34.4 \%$ of esotropia patients with an average deviation of $22.8 \mathrm{pd}$. Carruthers et al. ${ }^{9}$ found that $40 \%$ of esotropia and $33.3 \%$ of exotropia patients achieved less than $10 \mathrm{pd}$ strabismus. In one of the largest series, $\mathrm{Scott}^{7}$ reported better results, $56 \%$ of esotropia and $52 \%$ of exotropia adult cases achieving less than 10 pd deviation. The higher success rate for medial rectus muscle injection might be related to the greater concentration of singly innervated fibres in the global layer of the medial rectus muscle which are singularly and significantly affected by botulinum toxin. ${ }^{12}$

For large angle deviations BTA treatment is less effective and therefore surgery is advocated., ${ }^{2,9-11}$ For those who are willing to persist with injections instead of surgery, or when less than expected efficacy is obtained with the standard dose regimen, ${ }^{4,16}$ dose increments could be tried. The $\mathrm{LD}_{50}$ of BTA is far beyond the amount that can be injected into an extraocular muscle. ${ }^{17}$ Depending on the body mass, muscle volume and amount of deviation, a dose between 1.0 and $20.0 \mathrm{U}$ can be applied; however, moderate doses of 2.0-5.0 $\mathrm{U}$ are generally accepted. ${ }^{9,10,16}$ We have analysed the data on BTA produced in the UK, which is less potent than the US product, and unfortunately there have been no published guidelines for converting the doses between different brands of BTA. ${ }^{17,18}$ Therefore, it may be misleading to compare clinical trials using different brands in terms of a dose-effect relation. We have reported that the effect was dose-dependent in esotropia but not in exotropia. ${ }^{11}$ Elston et al., ${ }^{4}$ using British BTA, reported in a mixed group of esotropia and exotropia patients that the average maximum changes in the horizontal deviations were 38.5 pd with $3.12 \mathrm{U}$ and $22.5 \mathrm{pd}$ with $15.6 \mathrm{U}$ (dosages have been converted from the microgram notation used in the original article into units). They increased the dose when the initial response with a smaller dose was inadequate. They demonstrated that the percentages of patients achieving acceptable deviation with continued treatment were $81.8 \%(36 / 44)$ with $3.12 \mathrm{U}$ of BTA, and $45.2 \%(9 / 21)$ with $15.6 \mathrm{U}$ of BTA. We adjusted the amount of BTA between 2.5 and $20.0 \mathrm{U}$ according to the angle of deviation or depending on our previous experience in that case. Although there was not a statistical difference in the percentage of correction in esotropia or exotropia with less than or more than $10 \mathrm{U}$ of BTA $(41.4 \%$ and $36.9 \%$ in esotropia; $42.1 \%$ and $28.9 \%$ in exotropia), we believe that esotropia clinically responds better to higher doses.

The most common complications due to BTA are ptosis and induced vertical deviation, which are reported to be more common with medial rectus injection. ${ }^{6,7,9,16}$ However, their relations with dose increments were not clearly documented. Elston et al. ${ }^{4}$ reported the common complications of ptosis and vertical deviation together. Ten of 21 of their patients receiving more than $10 \mathrm{U}$ of BTA compared with 6 of 44 patients requiring less than $10 \mathrm{U}$ of BTA experienced these complications.

The frequency of ptosis after each injection for our esotropic patients was $18 \%$ and that for exotropia was $5 \%$. As we increased the dose of BTA to uncommon but safe practice levels, the risk of ptosis increased in patients with esotropia, but not in exotropia. Burns et al. ${ }^{19}$ stated that there was no significant relationship between common practice toxin dosages of $0.025-2.5 \mathrm{U}$ of American BTA and ptosis. Medial or lateral recti

Table 5. Frequency of temporary ptosis for each injection with different doses of BTA

\begin{tabular}{lcc}
\hline BTA dose & Esotropia (\%) & Exotropia (\%) \\
\hline$<10 \mathrm{U}$ & $1 / 13(8 \%)$ & $1 / 19(5 \%)$ \\
$\geqslant 10 \mathrm{U}$ & $6 / 25(24 \%)$ & $2 / 47(4 \%)$ \\
Total & $7 / 38(18 \%)$ & $3 / 66(5 \%)$ \\
\hline
\end{tabular}


injections of the toxin did not affect the risk of ptosis. Scott ${ }^{7}$ reported ptosis in $16 \%$ of adults and $25 \%$ of children, and in $31 \%$ of children in another study. ${ }^{16}$ Ptosis encountered with the use of BTA was found to be $1-53 \%$ in various studies. ${ }^{6,10,19,21}$ There are a number of possible reasons for the discrepancy in the frequency of ptosis between different reports: overlooked mild cases of ptosis, different dose regimens of BTA, or combined analysis of medial and lateral recti injections. Ptosis encountered after BTA injection is usually mild and should not disturb the patient. We experienced only two cases of ptosis severe enough to occlude the pupilla. This complication resolved completely in all cases in just a few weeks.

Incidence of induced vertical deviation for esotropic patients was $37 \%(7 / 19)$ and that for exotropia patients was $27 \%(8 / 30)$. Shippman et al. ${ }^{20}$ reported that esotropia cases were 8 times more likely to develop induced vertical deviation than exotropia patients. They used $1.8 \mathrm{U}$ of American BTA on average, which caused an average of $13 \mathrm{pd}$ vertical deviation in 9 patients of 17 . Infiltration of BTA to the surrounding extraocular muscles, particularly the vertical recti, is believed to cause vertical deviation. The higher incidence of vertical deviation in esotropic patents can be explained on the basis of the anatomical data regarding the normal distance between rectus muscle insertions. Data based on the measurements taken by $\mathrm{Apt}^{13}$ revealed that average distances between recti muscles were as follows: medial and inferior $5.9 \mathrm{~mm}$, medial and superior $7.5 \mathrm{~mm}$, lateral and inferior $8.0 \mathrm{~mm}$, lateral and superior $7.1 \mathrm{~mm}$. The slanted insertions of vertical recti muscles render them closer to the medial rectus insertion, which is well documented by Souza-Dias et al. ${ }^{14}$ Thus the distances between the medial rectus and the vertical recti are less than the distances between the lateral rectus and the vertical recti. Interestingly, all the vertical deviations encountered in esotropes were hypertropias. Three possible factors are responsible for hypertropia: first, the distance between medial and inferior recti is the shortest (5.9 mm); second, BTA diffuses to the depressor muscles of inferior rectus and superior oblique; and third, due to gravity BTA can infiltrate more readily into the inferior rectus.

Among exotropic patients, the incidence of hypotropia or hypertropia were similar, and significantly correlated with dose increment. This may be related to the data presented above: that the distance between superior and lateral recti is shorter than the distance between inferior and lateral recti, ${ }^{14}$ or inferior oblique involvement because of the close proximity of its insertion to the lateral rectus. The case notes of the hypotropic patients revealed that 2 patients developed a decrease of one level in their inferior oblique function after the injection (using a grading sysetm of $0-4$ ). We may have failed to observe mild differences in the other 3 patients.

The risk of post-treatment vertical deviation increases in parallel with the dose of BTA in both esotropes and exotropes. Vertical deviation was induced in $11 \%$ of esotropia and $8 \%$ of exotropia cases with less than $10 \mathrm{U}$ of BTA, whereas these figures increased to $60 \%$ and $39 \%$ respectively with more than $10 \mathrm{U}$ of BTA. However, within about a year, vertical deviation disappears in approximately $40 \%$ of cases and decreases in another $30 \%$. In a different study, recovery of the vertical deviation to the preinjection level took 3-8 weeks, and persisted in only one case after 6 months of follow-up. ${ }^{20}$

$\mathrm{Scott}^{22}$ reported induced ptosis and/or vertical deviation in $15-20 \%$ of horizontal extraocular muscle injections. In $18 \%$ of cases, BTA created more than 2 pd vertical deviation at 6 months. He tried the timely use of antitoxin to avoid these side-effects. He found that small doses of antitoxin injected to the levator or inferior rectus reduced but did not completely prevent the side-effects of ptosis and vertical deviation caused by BTA. We have no experience in the use of antitoxin for this purpose.

Increasing the dose of the BTA is clinically effective especially in larger deviation of esotropia, and to a much lesser extent in exotropia cases. However, this approach carries the increased risk of ptosis and induced vertical deviation. Only 2 patients were disturbed by ptosis severe enough to occlude the pupilla, although temporarily. None of the patients who experienced ptosis as a complication refused to have another injection for this reason whenever BTA was suggested as an option. Most of the time, vertical deviation is not bothersome for patients. However, following a considerable decrease in the horizontal deviation the remaining vertical deviation can be encountered by some patients. Interestingly, we found out that people are cosmetically more sensitive to the same amount of deviation occurring in the vertical plane compared with the horizontal plane. These possible complications are readily accepted by most patients given the ease of the method compared with surgery in certain instances.

\section{References}

1. Scott AB, Rosenbaum A, Collins CC. Pharmacological weakening of extraocular muscles. Invest Ophthalmol 1973;12:924-7.

2. Scott AB. Botulinum toxin injection of eye muscles to correct strabismus. Trans Am Ophthalmol Soc 1981;79:734-70.

3. Scott AB. Botulinum toxin injection into extraocular muscles as an alternative to strabismus surgery. J Pediatr Ophthalmol Strabismus 1980;17:21-5.

4. Elston JS, Lee JP, Powell CM, Hogg C, Clark P. Treatment of strabismus in adults with botulinum toxin $\mathrm{A}$. Br J Ophthalmol 1985;69:718-24.

5. Lee JP, Elston JS, Vickers S, Powell C, Kelly J, Hogg C. Botulinum toxin therapy for squint. Eye 1988;2:24-8.

6. Horgan SE, Lee JP, Bruce C. The long term use of botulinum toxin for adult strabismus. J Pediatr Ophthalmol Strabismus 1998;35:9-16.

7. Scott AB. Botulinum toxin treatment of strabismus. Focal points 1989: Clinical modules for ophthalmologists, vol VII, module 12. San Francisco: American Academy of Ophthalmology, 1989.

8. Biglan AW, Burnstine RA, Rogers GL, Saunders RA. Management of strabismus with botulinum A toxin. Ophthalmology 1989;96:935-43. 
9. Carruthers JD, Kennedy RA, Bagaric D. Botulinum toxin vs adjustable suture surgery in the treatment of horizontal misalignment in adult patients lacking fusion. Arch Ophthalmol 1990;108:1432-5.

10. Osako M, Keltner JL. Botulinum A toxin (Oculinum) in ophthalmology. Surv Ophthalmol 1991;36:28-46.

11. Abbasoğlu OE, Şener EC, Sanaç AŞ. Factors influencing success and dose-effect relation of botulinum A treatment. Eye 1996;10:385-91.

12. Spencer FR, McNeer KW. Botulinum toxic paralysis of adult monkey extraocular muscle. Arch Ophthalmol 1987;105:1703-11.

13. Apt L. An anatomical reevaluation of rectus muscle insertions. Trans Am Ophthalmol Soc 1980;78:365-75.

14. Souza-Dias C, Prieto-Diaz J, Vesugui CF. Topographical aspects of the insertions of the extraocular muscles. J Pediatr Ophthalmol Strabismus 1986;23:183-9.

15. Gammon JA, Gemmill M, Tiggers J, Leiman S. Botulinum chemodenervation treatment of strabismus. J Pediatr Ophthalmol Strabismus 1985;22:221-6.
16. Scott AB, Magoon EH, McNeer KW, Stager DR. Botulinum treatment of childhood strabismus. Ophthalmology 1990;97:1434-8.

17. Jankovic J, Brin MF. Therapeutic uses of botulinum toxin. $\mathrm{N}$ Engl J Med 1991;324:1186-94.

18. Brin MF, Blitzer A. Botulinum toxin: dangerous terminology errors [letter]. J R Soc Med 1993;86:494.

19. Burns CL, Gammon JA, Gemmill MC. Ptosis associated with botulinum toxin treatment of stabismus and blepharospasm. Ophthalmology 1986;93:1621-7.

20. Shippman S, Weseley AC, Cohen KR, Wang F. Secondary vertical deviations after Oculinum injection. Am Orthoptic J 1986;36:120-3.

21. Lingua RW. Sequelae of botulinum toxin injection. Am J Ophthalmol 1985;100:305-7.

22. Scott AB. Antitoxin reduces botulinum side effects. Eye 1988;2:29-32. 